\title{
Assessment of the relationship between endocan and obstructive sleep apnea severity
}

Hamdi Pusuroglu ${ }^{1}$, Umut Somuncu ${ }^{1}$, Ismail Bolat ${ }^{2}$, Ozgur Akgul'1, Hayriye Ak Yıldırım², Sinem Ozbay Ozyilmaz ${ }^{1}$, Vesile Ornek ${ }^{3}$, Ozgur Surgit ${ }^{1}$, Huseyin Karakurt ${ }^{1}$, Ayfer Utkusavas ${ }^{4}$, Nermina Alagic ${ }^{1}$, Aydın Yıldııım

\begin{abstract}
'Department of Cardiology, Mehmet Akif Ersoy Thoracic and Cardiovascular Surgery Center, Training and Research Hospital, Istanbul, Turkey 2Department of Cardiology, Fethiye State Hospital, Mugla, Turkey

${ }^{3}$ Department of Biochemistry, Mehmet Akif Ersoy Thoracic and Cardiovascular Surgery Center, Training and Research Hospital, Istanbul, Turkey

${ }^{4}$ Department of Chest, Mehmet Akif Ersoy Thoracic and Cardiovascular Surgery Center, Training and Research Hospital, Istanbul, Turkey
\end{abstract}

Submitted: 6 February 2018

Accepted: 9 May 2018

Arch Med Sci 2020; 16 (6): 1346-1352

DOI: https://doi.org/10.5114/aoms.2020.97764

Copyright @ 2020 Termedia \& Banach

\begin{abstract}
Introduction: Obstructive sleep apnea (OSA) and endothelial dysfunction are associated with cardiovascular risk factors and the development of atherosclerosis. Endocan is a marker of endothelial dysfunction, while obstructive sleep apnea is one of the causes of endothelial dysfunction. In this study, we investigated the relationship between endocan and obstructive sleep apnea severity.

Material and methods: A total of 179 patients with snoring complaints were included. All patients underwent polysomnography, and based on the results, the participations were allocated to the control group $(n=39)$ or to the obstructive sleep apnea group $(n=140)$. The OSA group was classified as having mild (apnea-hypopnea index $(\mathrm{AHI})=5-15 ; n=43$ ), moderate $(\mathrm{AHI}=15-30 ; n=42)$, or severe OSA $(\mathrm{AHI}>30 ; n=55)$. All participations had their endocan levels measured.

Results: Endocan levels in OSA patients were significantly higher than in the control group (11.8 (3.13-200) vs $3.13(3.13-23) \mathrm{ng} / \mathrm{ml}, p<0.001)$. Also, endocan levels were significantly higher in the severe OSA group than moderate and mild obstructive OSA (13.2 (3.13-200), 12.6 (3.13-200) and $8.44(3.13-50.5) \mathrm{ng} / \mathrm{ml}, p=0.015$, respectively). Multiple logistic regression analysis showed that smoking, age and endocan levels were independent predictors of OSA severity ( $p=0.024, p=0.037, p=0.004$, respectively).

Conclusions: Endocan seems to be a potential risk stratification marker in this patient population.
\end{abstract}

Key words: endocan, obstructive sleep apnea, obstructive sleep apnea severity.

\section{Introduction}

Obstructive sleep apnea (OSA) syndrome is defined by the presence of hypopnea and apnea, which are secondary to collapse of the upper airways during sleep. OSA is seen in $2-4 \%$ of adults and according to a study conducted in Turkey the prevalence of OSA was $0.9-1.9 \%$ [1, 2]. Hypertension, hyperlipidemia, and diabetes mellitus (DM) are well-

\author{
Corresponding author: \\ Dr. Sinem Ozbay Ozyilmaz \\ Department of Cardiology \\ Mehmet Akif Ersoy \\ Cardiovascular Research \\ and Training Hospital \\ Halkali, Kucukcekmece \\ Istanbul, Turkey \\ Phone: +90 2126922000 \\ (ext 1134) \\ Fax: +902124719494 \\ E-mail: \\ drsinemozbey@gmail.com
}


known risk factors of cardiovascular (CV) disease that cause endothelial dysfunction [3-5]. Hypoxia, hypercapnia, and fluctuations in blood pressure cause the release of vasoactive substances and impair endothelial function in patients with OSA. Endothelial function is often impaired even without obvious cardiac and vascular diseases in OSA $[6,7]$. Endothelial dysfunction is associated with increased CV events [8, 9]. Endothelial dysfunction is one of the reasons for the association between CV events and OSA.

Endocan is a dermatan sulfate (a proteoglycan) and increased levels of endocan indicate endothelial dysfunction [10]. Endocan has been detected at low levels in the serum of healthy individuals, while high levels have been reported in patients with endothelial dysfunction, sepsis and psoriasis [11-13].

Few studies in the literature have investigated the relationship between endocan levels and severity of OSA $[14,15]$. Furthermore, the sample size has been small in the studies that have been carried out. In the present study, we investigated the relationship between a control group and an OSA group to assess the relationship between severity of OSA and the level of endocan.

\section{Material and methods}

One hundred and seventy-nine patients without a history of cardiovascular disease who complained of snoring and were suspected to have OSA were evaluated at the outpatient clinic. All patients underwent polysomnography. They were monitored with a 58-channel polysomnograph (Sleep Screen, Compumedics, Australia) throughout the night. During the polysomnography, the following recordings were taken: 12-channel electroencephalogram (EEG), 2-channel electrooculogram (EOG), jaw and leg electromyogram (EMG), electrocardiogram (ECG), air flow via oronasal thermistor, chest and abdominal respiratory movements, oxygen saturation with a fingertip pulse oximeter, snoring with a tracheal microphone, and body posture. Sleep stages were scored based on Rechtschaffen and Kales's standard criteria [15]. Interruptions in oronasal air flow for longer than $10 \mathrm{~s}$ were classified as apnea; decreases in oxygen saturation by $3 \%$ for $10 \mathrm{~s}$ or more or a minimum of $50 \%$ decrease in the air flow due to arousal were classified as hypopnea; and the apnea and hypopnea counts per hour were recorded as the AHI [16]. The OSAS diagnosis was made on the basis of $\mathrm{AHI}>5$. OSA patients were assigned to the mild ( $\mathrm{AHI}=5-15 ; n=43)$, moderate $(\mathrm{AHI}=15-30 ; n=42)$, and severe OSA (AHI $>30 ; n=55$ ) subgroups. Sleep stages were scored following standard criteria with 30-second epochs and were reviewed and verified by a certified sleep physician.
The study was approved by the Ethics Committee in the Mehmet Akif Ersoy Thoracic and Cardiovascular Surgery Center, Training and Research Hospital. All patients signed an informed consent form. This study was performed in accordance with the requirements of the Declaration of Helsinki.

Hypertension was defined as an office blood pressure (OBP) of $\geq 140 / 90 \mathrm{~mm} \mathrm{Hg}$ or active use of antihypertensive drugs [17]. DM was defined based on the American Diabetes Association criteria (fasting serum glucose $\geq 126 \mathrm{mg} / \mathrm{dl}$ (7 mmol/l), non-fasting glucose $\geq 200 \mathrm{mg} / \mathrm{dl}$ $(11.1 \mathrm{mmol} / \mathrm{l})$, or active use of anti-diabetic treatment) [18]. Body mass index (BMI) was calculated by dividing weight $(\mathrm{kg})$ by height squared $\left(\mathrm{m}^{2}\right)$. Daily smoking habits of participations were recorded. Current smokers were defined as those who have smoked more than 100 cigarettes during their lifetime and also have smoked during the last month [19].

Hyperlipidemia was defined as fasting total serum cholesterol > $240 \mathrm{mg} / \mathrm{dl}$, low-density lipoprotein (LDL) cholesterol > $130 \mathrm{mg} / \mathrm{dl}$, serum triglycerides > $180 \mathrm{mg} / \mathrm{dl}$, or the patient's use of lipid-lowering drugs due to a history of hypercholesterolemia. Family history was defined as premature CV disease occurring in first-degree relatives aged $<55$ years for men and $<65$ years for women.

\section{Blood sampling}

Standard laboratory parameters, including hematocrit and creatinine levels and lipid profiles, were determined with standard methods. Blood high-sensitivity C-reactive protein (hsCRP) levels were measured using a turbidimetric method (Cobas C501 Autoanalyzer; Roche Diagnostics, Mannheim, Germany). Serum endocan levels were measured with an Aviscer Bioscience brand human endothelial cell-specific molecule 1 (ESM-1) (catalog no: SK00318-6) and through the enzyme-linked immunosorbent assay (ELISA) method using Elisa Biotek ELX800 Microplate Reader devices (intra-assay coefficient of variability (CV), 6-8\%, inter-assay CV, 10-12\%).

\section{Statistical analysis}

Statistical analyses were performed using IBM SPSS Statistics Version 20 (IBM Corp., Armonk, NY, USA). The variables were investigated using visual (histograms, probability plots) and analytical methods (Kolmogorov-Smirnov) to determine whether they were normally distributed. Descriptive results are expressed as means and standard deviations (SDs) for normally distributed variables, medians and maximum-minimum for 
Table I. Characteristics of the study population

\begin{tabular}{|c|c|c|c|}
\hline Variable & Non-OSA $(n=39)$ & OSA $(n=140)$ & $P$-value \\
\hline Gender (male), $n(\%)$ & $33(84.6)$ & $101(72.1)$ & 0.145 \\
\hline Age [years] & $52.3 \pm 6.5$ & $52.7 \pm 6.7$ & 0.717 \\
\hline BMI $\left[\mathrm{kg} / \mathrm{m}^{2}\right]$ & $32.3 \pm 5.0$ & $35.9 \pm 5.4$ & 0.007 \\
\hline Smoking, $n(\%)$ & $9(23.1)$ & $78(55.7)$ & $<0.001$ \\
\hline Diabetes, $n(\%)$ & $6(15.4)$ & $32(22.9)$ & 0.381 \\
\hline Family history, $n$ (\%) & $3(7.7)$ & $8(5.7)$ & 0.707 \\
\hline Hypertension, $n$ (\%) & $9(23.1)$ & $54(38.6)$ & 0.089 \\
\hline Hyperlipidemia, $n$ (\%) & $3(7.7)$ & $9(6.4)$ & 0.726 \\
\hline Creatinine [mg/dl] & $0.79 \pm 0.16$ & $0.78 \pm 0.18$ & 0.964 \\
\hline Triglyceride [mg/dl] & $142 \pm 78$ & $183 \pm 106$ & 0.180 \\
\hline Total cholesterol [mg/dl] & $210 \pm 50$ & $215 \pm 42$ & 0.725 \\
\hline LDL cholesterol [mg/dl] & $135 \pm 45$ & $138 \pm 36$ & 0.685 \\
\hline HDL cholesterol [mg/dl] & $47 \pm 15$ & $44 \pm 14$ & 0.515 \\
\hline Hematocrit (\%) & $42.8 \pm 4.7$ & $42.2 \pm 3.9$ & 0.398 \\
\hline Glucose $[\mathrm{mg} / \mathrm{dl}]$ & $105 \pm 17$ & $116 \pm 35$ & 0.062 \\
\hline $\mathrm{hsCRP}[\mathrm{mg} / \mathrm{dl}]$ & $5.1 \pm 3.1$ & $5.5 \pm 4.1$ & 0.756 \\
\hline Endocan, median (minimum-maximum) $[\mathrm{ng} / \mathrm{ml}]$ & $3.13(3.13-23)$ & $11.8(3.13-200)$ & $<0.001$ \\
\hline
\end{tabular}

Values expressed as mean $\pm S D$ or number (percent) unless indicated otherwise. BMI - body mass index, eGFR - estimate glomerular filtration rate, hSCRP - high-sensitivity C-reactive protein, $L D L$ - low-density lipoprotein, $H D L$ - high-density lipoprotein.

the non-normally distributed and percentages for categorical variables. Differences between continuous and categorical variables among the groups were assessed using one-way analysis of variance (ANOVA) and the Kruskal-Wallis and $\chi^{2}$ tests. The Mann-Whitney $U$ or Tukey test was performed to test the significance of pairwise differences using Bonferroni correction to adjust for multiple comparisons. Multiple logistic regression analysis, which included endocan and others variables, was performed to identify independent predictors of OSA severity. An overall 5\% type-I error level was used to infer statistical significance.

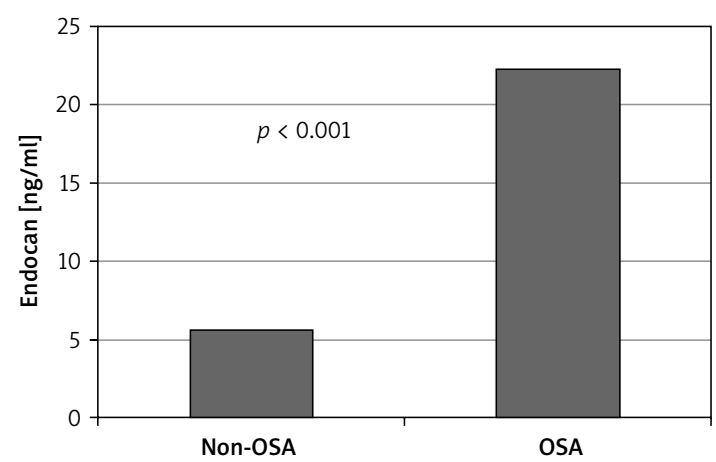

Figure 1. Endocan levels in obstructive sleep apnea (OSA) and non-OSA participations

\section{Results}

The study sample consisted of 179 patients with 140 being diagnosed as OSA and 39 non-OSA patients. Endocan levels and BMI were significantly higher in OSA patients than in the control group (11.8 (3.13-200) vs. $3.13(3.13-23) \mathrm{ng} / \mathrm{ml}$, $p<0.001 ; 32.3 \pm 5.0$ vs. $35.9 \pm 5.4, p<0.007$; Table I, Figure 1).

Other demographic and laboratory results were statistically similar between the groups (Table I). Levels of hsCRP and endocan were significantly higher in the severe OSA group than the mild and moderate OSA group ( $p=0.008, p=0.015$, respectively; Table II). Other demographic characteristics and laboratory results were not statistically different between the groups (Table II; Figure 2).

Univariate logistic regression analysis showed that smoking, BMI, age and endocan levels were predictors of OSA severity. After multiple logistic regression analysis, smoking, age and endocan levels were determined to be independent predictors of OSA severity $(p=0.024, p=0.037, p=0.004$, respectively; Table III).

\section{Discussion}

In this study, endocan levels were significantly higher in patients with OSA, and the results also 
Table II. Characteristics of the study population

\begin{tabular}{|lcccc|}
\hline Variable & $\begin{array}{c}\text { Mild OSA } \\
(n=43)\end{array}$ & $\begin{array}{c}\text { Moderate OSA } \\
(n=42)\end{array}$ & $\begin{array}{c}\text { Severe OSA } \\
(n=55)\end{array}$ & $P$-value \\
\hline Gender (male), $n$ (\%) & $27(62.7)$ & $29(69.0)$ & $45(81.8)$ & 0.099 \\
\hline Age [years] & $52.4 \pm 6.0$ & $53.1 \pm 6.6$ & $52.7 \pm 7.3$ & 0.904 \\
\hline BMl [kg/m²] & $34.0 \pm 4.6$ & $34.9 \pm 5.7$ & $35.8 \pm 6.2$ & 0.281 \\
\hline Smoking, $n$ (\%) & $20(46.5)$ & $23(54.8)$ & $35(63.5)$ & 0.236 \\
\hline Diabetes, $n$ (\%) & $7(16.3)$ & $7(16.7)$ & $18(32.7)$ & 0.082 \\
\hline Family history, $n$ (\%) & $2(4.8)$ & $6(14.3)$ & $2(3.6)$ & 0.110 \\
\hline Hypertension, $n$ (\%) & $15(34.9)$ & $13(31.0)$ & $26(47.3)$ & 0.219 \\
\hline Hyperlipidemia, $n$ (\%) & $5(11.6)$ & $2(4.8)$ & $2(3.6)$ & 0.242 \\
\hline Creatinine [mg/dl] & $0.75 \pm 0.18$ & $0.75 \pm 0.16$ & $0.84 \pm 0.45$ & 0.391 \\
\hline Triglyceride [mg/dl] & $191 \pm 123$ & $176 \pm 104$ & $181 \pm 93$ & 0.815 \\
\hline Total cholesterol [mg/dl] & $217 \pm 40$ & $220 \pm 44$ & $208 \pm 43$ & 0.385 \\
\hline LDL cholesterol [mg/dl] & $137 \pm 36$ & $145 \pm 36$ & $133 \pm 31$ & 0209 \\
\hline HDL cholesterol [mg/dl] & $43 \pm 7$ & $46 \pm 20$ & $44 \pm 11$ & 0.584 \\
\hline Hematocrit (\%) & $41.2 \pm 3.9$ & $42.6 \pm 4.9$ & $42.3 \pm 4.1$ & 0.644 \\
\hline Glucose [mg/dl] & $113 \pm 35$ & $108 \pm 16$ & $123 \pm 43$ & 0.197 \\
\hline hsCRP [mg/dl] & $4.4 \pm 4.1$ & $3.7 \pm 5.4$ & $13.2(3.13-200)$ & 0.008 \\
\hline $\begin{array}{l}\text { Endocan, median } \\
\text { (minimum-maximum) }\end{array}$ & $8.44(3.13-50.5)$ & $12.6(3.13-200)$ & & \\
\hline Valml] & & & & 0.015 \\
\hline
\end{tabular}

Values expressed as mean $\pm S D$ or number (percent) unless indicated otherwise. BMI - body mass index, eGFR - estimate glomerular filtration rate, hSCRP - high-sensitivity C-reactive protein, $L D L$ - low density lipoprotein, HDL - high-density lipoprotein.

showed that a high level of endocan is an independent predictor of OSA severity. OSA syndrome is a substantial health problem, with a prevalence of $5-20 \%$ in the general population [20]. OSA has been determined to be an independent risk factor for CV events and mortality [21, 22]. Moreover, it was reported as a risk factor for the development of coronary artery diseases [23, 24]. Many factors observed in OSA patients, such as hypoxemia, systemic hypertension, and increased sympathetic activity, are considered to lead to atherosclerosis development [24]. Hypoxia lowers the nitric oxide level and causes increases in oxidative stress, endothelial dysfunction and LDL oxidation [25].

Endothelial dysfunction is associated with increased CV events $[8,9,26]$. It is often observed in patients with diseases associated with CV events, such as hypertension, hyperlipidemia, DM and smoking [3-5, 27]. Sleep apnea and associated factors cause a deterioration of endothelial function. Hypoxia, hypercapnia, and fluctuations in blood pressure impair endothelial function and result in the release of vasoactive substances in patients with OSA. Moreover, endothelial function is impaired in patients with OSA [6, 7]. Endothelial dysfunction is an early sign of vascular injury, and one of the causes of the development of CV disease in patients with OSA is thought to be the development of endothelial dysfunction. At the same time, the development of endothelial dysfunction has been shown to be associated with mortality and morbidity in many different diseases $[8,9,26]$.

The prognostic significance of endocan level has been demonstrated in a number of diseases, such as hypertension, chronic renal disease, sepsis and transplant rejection [12, 28-30]. In the present study, it was observed that higher serum endocan levels were evident in patients with severe OSA.

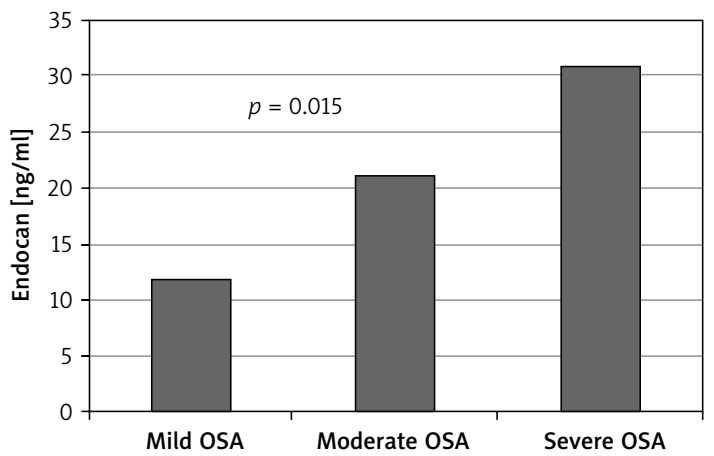

Figure 2. Endocan levels in mild, moderate and severe obstructive sleep apnea 
Table III. Multivariate logistic regression analysis of obstructive sleep apnea severity

\begin{tabular}{|c|c|c|c|c|}
\hline Parameter & $\begin{array}{c}\text { Univariate analysis } \\
\text { OR }(95 \% \mathrm{Cl})\end{array}$ & $P$-value & $\begin{array}{l}\text { Multivariate analysis } \\
\text { OR }(95 \% \mathrm{Cl})\end{array}$ & $P$-value \\
\hline Smoking & $1.040(1.016-1.066)$ & 0.001 & $1.031(1.004-1.060)$ & 0.024 \\
\hline BMI & $1.053(0.996-1.113)$ & 0.048 & $1.050(0.984-1.120)$ & 0.142 \\
\hline Age & $1.060(1.012-1.111)$ & 0.014 & 1.061 (1.004-1.121) & 0.037 \\
\hline CRP & $1.030(0.977-1.087)$ & 0.273 & & \\
\hline Sex (male) & $0.848(0.431-1.667)$ & 0.632 & & \\
\hline $\mathrm{N} / \mathrm{L}$ ratio & $1.135(0.744-1.731)$ & 0.557 & & \\
\hline Hypertension & $1.625(0.870-3.037)$ & 0.128 & & \\
\hline Hyperlipidemia & $0.398(0.115-1.373)$ & 0.145 & & \\
\hline Diabetes mellitus & $1.843(0.873-3.890)$ & 0.109 & & \\
\hline Endocan & 1.078 (1.040-1.119) & $<0.001$ & $1.076(1.035-1.117)$ & 0.004 \\
\hline
\end{tabular}

$B M I$ - body mass index, hSCRP - high-sensitivity C-reactive protein, OSA - obstructive sleep apnea.

Also, we showed that the serum endocan level is an independent predictor of severe OSA. Recently, in a small study (40 patients), endocan levels were found to be higher in OSA patients compared with the control group [31]. The same study also showed that the serum endocan levels fall after treatment with CPAP [31]. According to this result, serum endocan levels may be a good marker for monitoring the effectiveness of treatment and severity of OSA.

In recent studies, it has been shown that the incidence of OSA increased with age, and there was a correlation between OSA and mortality and morbidity [32, 33]. It was found in several epidemiological studies that there is a significant relationship between upper airway apneas, smoking, and inflammation, and unstable sleep at night was caused by nicotine withdrawal [34, 35]. In the present study, there was an association between the severity of OSA and age and smoking.

Obesity is a major risk factor for the development of OSA. A low-calorie diet and bariatric surgery help to reduce the severity of OSA [36]. Moreover, it has been shown that an increase in weight can cause an increase in the AHI [37]. In this study, increasing BMI was significantly associated with the severity of OSA in univariate analysis ( $p=$ $0.009, p=0.075$, respectively), but there was no association in multivariate analysis.

The inflammatory process is associated with OSA [38]. hsCRP is an important marker of inflammation related to interleukin [39]. High hsCRP, tumor necrosis factor- $\alpha$, interleukin- 6 and interleukin-1 are increased in patients with OSA [40]. Increases in inflammation caused by hypoxia represent another cause of atherosclerosis observed along with OSA. In line with previous studies, hsCRP also was found to be higher among patients with severe OSA in the present research [40]. According to the previous studies hsCRP has been found to be associated with cardiovascular risk factors such as obesity, hyperglycemia and hypertension [41]. In our study these factors were not significantly different among OSA groups. In other OSA studies it has been shown that patients with severe OSA had coronary atherosclerosis and endothelial dysfunction more frequently $[28,42]$. hsCRP is found in atheromatous plaque and it is associated with vascular dysfunction. Increased hsCRP levels in patients with severe OSA may be an indicator of endothelial dysfunction and coronary atherosclerosis.

Our study has several limitations. First, it was a non-randomized study, and therefore subject to selection bias. Moreover, we could not assess endothelial dysfunction by flow-mediated dilatation (FMD) and other validated techniques. However, in previous studies serum endocan levels were shown to be independently correlated with FMD $[28,31]$. Second, CPAP, metabolic syndrome and pharmacological therapy can alter endothelial function [31, 43]. In this study the relationships between CPAP, metabolic syndrome and pharmacological treatment and endocan levels were not investigated. Finally, the long-term results were not presented in this article.

In conclusion, high levels of endocan were associated with the severity of OSA. Endocan may be useful for risk classification in this patient group.

\section{Conflict of interest}

The authors declare no conflict of interest.

\section{References}

1. Young T, Palta M, Dempsey J, et al. The occurence of sleep-disordered breathing among middle-aged adults. N Engl J Med 1993; 328: 1230-5. 
2. Köktürk O, Tatlıcıoğlu T, Kemaloğlu Y, Fırat H, Cetin N. Habituel horlaması olan olgularda obstructive sleep apne sendromu prevelansı. Tüberküloz ve Toraks 1997; 45: 7-11.

3. Pedrinelli R, Giampietro O, Carmassi F, et al. Microalbumuria endothelial dysfunction in essential hypertension. Lancet 1994; 344: 14-8.

4. Lee IK, Kım HS, Bae JH. Endothelial dysfunction: its relationship with acute hyperglycaemia and hyperlipidemia. Int J Clin Pract Suppl 2002; 129: 59-64.

5. Ciarla MV, Bocciarelli A, Di Gregorio S, et al. Autoantibodies and endothelial dysfunction in well controlled, uncomplicated insulin-dependent diabetes mellitus patients. Atherosclerosis 2001; 158: 241-6.

6. Schulz R, Schmidt D, Blum A, et al. Decreased plasma levels of nitric oxide derivaties in obstructive sleep apnoea: response to CPAP therapy. Thorax 2000; 55: 1046-51.

7. Kato M, Roberts-Thomson P, Phillips BG, et al. Impairment of endothelium-dependent vasodilation of resistance vessels in patients with obstructive sleep apnea. Circulation 2000; 102: 2607-10.

8. Bonetti PO, Lerman LO, Lerman A. Endothelial dysfunction: a marker of atherosclerotic risk. Arterioscler Thromb Vasc Biol 2003; 23: 168-75.

9. Vita JA, Keaney Jr JF. Endothelial function: barometer for vascular risk? Circulation 2002; 106: 640-2.

10. Lassalle $P$, Molet $\mathrm{S}$, Janin A, et al. ESM-1 is novel human endothelial cell-specific molecule 1 by specific molecule expressed in lung and regulated by cytokines. J Biol Chem 1996; 271: 20458-64.

11. Bechard D, Meignin V, Scherpereel A, et al. Characterization of the secreted form of endothelial-cell-specific molecule 1 by specific monoclonal antibodies. J Vasc Res 2000; 37: 417-25.

12. Scherpereel A, Depontieu F, Grigoriu B, et al. Endocan, a new endothelial marker in human sepsis. Crit Care Med 2006; 34: 532-7.

13. Mihajlovic DM, Lendak DF, Brkic SV, et al. Endocan is useful biomarker of survival and severity in sepsis. Microvasc Res 2014; 93: 92-7.

14. Ozden K, Polat M, Ozturk S, Bugdaycı G. Assessment of subclinical cardiac damage in chronicplaque psoriasis patients:a case control study. Arch Med Sci Atheroscler Dis 2016; 1: e126-32.

15. Kanbay A, Ceylan E, Köseoğlu Hi, et al. Endocan: a novel predictor of endothelial dysfunction in obstructive sleep apnea syndrome. Clin Respir J 2018; 12: 84-90.

16. Bingol Z, Kose M, Pıhtılı A, Akpınar T, Tukek T, Kıyan E Serum endothelial cell specific molecule-1 (endocan) levels in patients with obstructive sleep apnea. Biomark Med 2016; 10: 177-84.

17. Mancia G, Fagard R, Narkiewicz K, et al. 2013 ESH/ESC guidelines for the management of arterial hypertension: the Task Force for the Management of Arterial Hypertension of the European Society of Hypertension (ESH) and of the European Society of Cardiology (ESC) Eur Heart J 2013; 34: 2159-219.

18. Expert Committee on the Diagnosis and Classification of Diabetes Mellitus. Report of the expert committee on the diagnosis and classification of diabetes mellitus. Diabetes Care 2003; 26: S5-20.

19. Vannimenus C, Bricout H, Le Rouzic O, et al. ALTAK Study Group. Compared characteristics of current vs.past smokers at the time of diagnosis of a first-time lung or head and neck cancer: a cross-sectional study. BMC Cancer 2018; 18: 372.
20. Young T, Palta M, Dempsey J, Skatrud J, Weber S, Badr S. The occurrence of sleep disordered breathing among middle-aged adults. N Engl J Med 1993; 328: 1230-5.

21. Marin JM, Carrizo SJ, Vicente E, Agusti AG. Long-term cardiovascular outcomes in men with obstructive sleep apnoea-hypopnoea with or without treatment with continuous positive airway pressure: an observational study. Lancet 2005; 365: 1046-53.

22. Yaggi HK, Concato J, Kernan WN, Lichtman JH, Brass LM, Mohsenin V. Obstructive sleep apnea as a risk factor for stroke and death. N Engl J Med 2005; 353: 2034-41.

23. Mooe T, Rabben T, Wiklund U, Franklin KA, Eriksson P. Sleep-disordered breathing in men with coronary artery disease. Chest 1996; 109: 659-63.

24. Schafer H, Koehler U, Ploch T, Peter JH. Sleep-related myocardial ischemia and sleep structure in patients with obstructive sleep apnea and coronary heart disease. Chest 1997; 111: 387-93.

25. Phelan MW, Faller DV. Hypoxia decreases constitutive nitric oxide synthase transcript and protein in cultured endothelial cells. J Cell Physiol 1996; 167: 469-76.

26. Modena MG, Bonetti L, Coppi F, Bursi F, Rossi R. Prognostic role of reversible endothelial dysfunction in hypertensive postmenopausal wommen. J Am Coll Cardiol 2002; 40: 505-10.

27. Milionis HJ, Jeremy JY, Mikhailidis DP. Regarding smoking is associated with dose-related increase of intima-media thickness and endothelial dysfunction. Angiology 1999; 50: 959-61.

28. Balta S, Mikhailidis DP, Demirkol S, et al. Endocan a novel inflammatory indicator in newly diagnosed patients with hypertension: a pilot study. Angiology 2014; 65: 773-7.

29. Su YH, Shu KH, Hu CP, et al. Serum endocan correlated with stage of chronic kidney disease and deterioration in renal transplant recipients. Transplant Proc 2014; 46: 323-7.

30. Yilmaz MI, Siriopol D, Saglam M, et al. Plasma endocan levels associate with inflammation, vascular abnormalities, cardiovascular events, and survival in chronic kidney disease. Kidney Int 2014; 86: 1213-20.

31. Altintas N, Mutlu LC, Akkoyun DC, et al. Effect of CPAP on new endothelial dysfunction marker, endocan, in people with obstructive sleep apnea. Angiology 2016; 67: 364-74.

32. Launois SH, Pepin JL, Levy P. Sleep apnea in elderly: a specific entity? Sleep Med Rev 2007; 11: 87-97.

33. Wetter DW, Young TB, Bidwell TR, Badr MS, Palta M. Smoking as a risk factor for sleep-disordered breathing. Arch Intern Med 1994; 154: 2219-24.

34. Pack AI, Cola MF, Goldszmidt A, Ogilvie MD, Gottschalk A. Correlation between oscillations in ventilation and frequency content of the electroencephalogram. J Appl Physiol 1992; 72: 985-92.

35. Koskenvuo M, Partinen M, Kaprio J, et al. Snoring and cardiovascular risk factors. Ann Med 1994; 26: 371-6.

36. Grunstein RR, StenlöfK, Hedner JA, Peltonen M, Karason K, Sjöström L. Two year reduction in sleep apnea symptoms and associated diabetes incidence after weight loss in severe obesity. Sleep 2007; 30: 703-10.

37. Newman AB, Foster G, Givelber R, Nieto FJ, Redline S, Young T. Progression and regression of sleep-disordered breathing with changes in weight: the Sleep Heart Health Study. Arch Intern Med 2005; 165: 2408-13.

38. Vgontzas AN, Papanicolaou Da, Bixler EO, et al. Elevation of plasma cytokines in disorders of excessive daytime sleepiness: role of sleep disturbance and obesity. J Clin Endocrinol Metab 1997; 82: 1313-6. 
39. Castell J, Gomez-Lechion M, David M. Acute phase response of human hepatocyte: regulation of acute-phase protein synthesis by interleukin-6. Hepatology 1990; 12: 1179-86.

40. Dursunoglu N, Dursunoglu D. Obstructive sleep apnea syndrome, endothelial dysfunction and coronary atherosclerosis. Tuberk Toraks 2005; 53: 299-306.

41. Gaines J, Kong L, Li M, et al. C-reactive protein improves the ability to detect cardiometabolic risk in mild-to-moderate obstructive sleep apnea. Physiol Rep 2017; 5: e13454.

42. Pusuroglu H, Somuncu U, Bolat I, et al. Galectin-3 is associated with coronary plaque burden and obstructive sleep apnea syndrome severity. Kardiol Pol 2017; 75: 351-9.

43. Halici I, Palabiyik SS, Guducu-Tufekci F, Ozbek-Bilgin A Cayir A. How many participations in your study had metabolic syndrome (MetS)? Endothelial dysfunction biomarker, endothelial cell-specific molecule-1, and pediatric metabolic syndrome. Pediatr Int 2016; 58: 1124-9. 